\title{
UTILIZAÇÃO DE SURFACTANTES, NA POLPAÇÃO KRAFT DE MADEIRA DE EUCALIPTO, COMO AUXILIAR NA REMOÇÃO DE EXTRATIVOS LIPOFÍLICOS ${ }^{1}$
}

\author{
Deusanilde de Jesus Silva², José Lívio Gomide ${ }^{3}$ e Jorge Luiz Colodette ${ }^{3}$
}

\begin{abstract}
RESUMO - Problemas de deposição de "pitch" em fábricas de celulose e de papel são atribuídos aos extrativos lipofílicos existentes na madeira. Uma das maneiras mais eficientes de controlar essa deposição é através da remoção de seus precursores do sistema, logo que possível, nas etapas de cozimento, lavagem da polpa marrom e pré-deslignificação com oxigênio. O uso de surfactantes como aditivos da polpação tem sido investigado, mas há grande deficiência de informações técnicas, e a aplicação industrial é, ainda, incipiente. A proposta deste trabalho foi analisar a viabilidade de minimizar a deposição de "pitch", intensificando a remoção de suas substâncias precursoras na etapa de polpação pelo uso de tensoativos sintéticos com propriedades umectantes e solubilizantes. Foram testados 20 princípios ativos de surfactantes em cozimento kraft convencional de madeira de eucalipto. Os resultados, alguns estatisticamente significativos, apontaram redução do teor de substâncias lipofílicas na polpa marrom. Foi observado que a remoção dos extrativos lipofílicos da madeira é afetada, inversamente, pelo teor de óxido de eteno na molécula do surfactante. Outros parâmetros de cozimento, como deslignificação, rendimento, teor de rejeitos e viscosidade da polpa, foram também avaliados.
\end{abstract}

Palavras-chave: Eucalyptus, polpação kraft, aditivo, surfactantes, tensoativos e extrativos.

\section{SURFACTANT UTILIZATION IN KRAFT PULPING OF EUCALYPTUS WOOD TO IMPROVE LIPOPHILIC EXTRACTIVES REMOVAL}

\begin{abstract}
Extractives are pitch precursors and may decrease pulping efficiency and affect pulp quality. Probably, the most efficient way to minimize pitch problems is to remove their precursors from the system during cooking, pulp washing and oxygen delignification. Use of surfactants as pulping additives has been investigated but technical information is deficient and industrial application is very incipient. The objective of this study was to analyze the performance of different surfactants as additives for kraft pulping of Eucalyptus wood. Twenty surfactants with different basic chemical structures were used. The results demonstrated that utilization of surfactant presents promising results as an additive for kraft pulping.
\end{abstract}

Key words: Eucalyptus, kraft pulping, additive, surfactants, extractives.

\section{INTRODUÇÃO}

O uso de surfactantes como aditivos na polpação de madeira ainda é pouco significativo, apesar de estudos de utilização comercial terem sido intensificados nos últimos anos, inclusive no Brasil. No passado, a finalidade principal de se usarem substâncias tensoativas em fábricas de celulose era aumentar o grau de pureza da polpa, visando à produção de celulose para dissolução. Atualmente, além dessa aplicação, essas substâncias têm sido testadas como auxiliar de cozimento para outras finalidades, como para aumento da eficiência

\footnotetext{
${ }^{1}$ Recebido em 27.01.2003 e aceito para publicação em 10.08.2004.

${ }^{2}$ Consultora Técnica da Fiber Technologies Consultoria e Serviços Técnicos S/C Ltda, FiberTechs.

${ }^{3}$ Departamento de Engenharia Florestal da UFV. Viçosa, MG. E-mail: <jlgomide@ ufv.br> e <colodette@ufv.br>.
} 
de impregnação dos cavacos, redução do consumo de álcali, redução do teor de rejeito e decréscimo do número kappa da polpa. Esses possíveis benefícios ocorreriam em razão da redução significativa da tensão superficial do licor de cozimento ocasionada pelos surfactantes. Outra finalidade dos surfactantes, ainda considerada como potencial, é a utilização como auxiliar na solubilização de extrativos lipofílicos da madeira.

Poucos são os trabalhos que avaliam a utilização de substâncias tensoativas em processos de cozimento kraft de madeira de fibra curta (FIŠEROVÁ e LU•ÁKOVÁ, 2000; DUGGIRALA, 1999b; SILVAJR. et al., 1997). Nessas literaturas, os princípios ativos utilizados não foram caracterizados de forma clara, mas a melhoria das variáveis de cozimento e de qualidade da polpa foi considerada significativa.

Dentre os diferentes tipos de surfactantes disponíveis comercialmente, pode-se verificar um consenso nas diferentes literaturas consultadas que os melhores resultados foram alcançados quando utilizadas substâncias à base de hidrocarbonetos, ou seja, os álcoois etoxilados. Esses compostos foram usados como auxiliar de cozimento (FISEROVÁ e LUZAKOVÁ, 2000; DUGGIRALA, 1999a e 1999b; CHEN, 1994) e como agente de remoção de resina na lavagem da polpa (BORCHARDT et al., 1997; O'MERA e PATERSON, 1960). Em algumas fábricas de celulose kraft é comum a utilização de álcoois etoxilados como agentes de controle de "pitch" (BORCHARDT et al., 1997).

Estudo realizado com madeira de folhosa indicou que surfactantes à base de silicone apresentaram eficiência inferior quando comparados com os surfactantes à base de hidrocarbonetos (DUGGIRALA, 1999b). Em toda a literatura consultada não foi encontrado nenhum estudo que utilizasse fluorsurfactantes como aditivo de polpação.

Os surfactantes já foram, também, estudados em associação com a antraquinona, com benefícios satisfatórios, segundo Silva Jr. et al. (1997).

O objetivo deste trabalho foi avaliar 20 princípios ativos de surfactantes comerciais como auxiliar na remoção de extrativos lipofílicos durante na polpação kraft de madeira de eucalipto.

\section{MATERIAL E MÉTODOS}

Foram utilizadas duas amostras de cavacos industriais de madeira de eucalipto (Fases 1 e 2). Os cavacos foram classificados manualmente, sendo selecionada a fração que atravessou a peneira classificatória de 32 × $32 \mathrm{~mm}$ e que ficou retida em peneira de 16 x $16 \mathrm{~mm}$. Os cavacos com defeitos de corte, os pedaços de cascas e nós foram excluídos. Após classificação e secagem ao ar livre, os cavacos foram acondicionados em sacos de polietileno para uniformização e conservação do teor de umidade.

Na fase 1 deste trabalho foram utilizados três tipos de surfactantes (fluorados, silicone e hidrocarbonetos), totalizando nove amostras. No Quadro 1 são citados esses surfactantes e suas características.

Na fase 2 do trabalho, considerando os resultados alcançados na fase 1 , foram utilizados outros 11 surfactantes, todos álcoois etoxilados. No Quadro 2 são mostrados os surfactantes usados na fase 2 e respectivas características.

Quadro 1 - Características dos surfactantes utilizados na fase 1 Table 1 -Characteristics of surfactants used for phase 1

\begin{tabular}{|c|c|c|c|c|c|}
\hline Número & Surfactante & Tipo & Carga Iônica & HLB $^{1}$ & Óxido de Eteno, \% \\
\hline 1 & Fluorado & Fluor & Não iônico & 10,7 & 53,3 \\
\hline 2 & Fluorado & Fluor & Aniônico ${ }^{2}$ & - & 12,4 \\
\hline 3 & Silicone & Silicone & Não iônico & 8 & 55,9 \\
\hline 4 & Álcool etoxilado linear & Hidrocarboneto & Não iônico & 11,7 & 58,7 \\
\hline 5 & Álcool etoxilado linear & Hidrocarboneto & Não iônico & 13,1 & 65,4 \\
\hline 6 & Álcool etoxilado linear & Hidrocarboneto & Não iônico & 16,9 & 84,0 \\
\hline 7 & Álcool etoxilado linear & Hidrocarboneto & Aniônico ${ }^{2}$ & - & 49,8 \\
\hline 8 & Álcool etoxilado linear & Hidrocarboneto & Aniônico ${ }^{2}$ & - & 57,0 \\
\hline 9 & Álcool etoxilado linear & Hidrocarboneto & Aniônico ${ }^{2}$ & - & 79,2 \\
\hline
\end{tabular}

${ }^{1}$ Relação entre as frações hidrofóbica e hidrofílica. ${ }^{2}$ Fosfatado.

R. Árvore, Viçosa-MG, v.28, n.6, p.911-917, 2004 
Quadro 2 - Características dos surfactantes utilizados na fase 2 Table 2 - Characteristics of surfactants used for phase 2

\begin{tabular}{|c|c|c|c|c|c|}
\hline Número & Surfactante & Tipo & Carga Iônica & $\mathrm{HLB}^{1}$ & Óxido de Eteno, \% \\
\hline 11 & Álcool etoxilado linear & Hidrocarboneto & Não iônico & 9,7 & 48,6 \\
\hline 12 & Álcool etoxilado linear & Hidrocarboneto & Aniônico ${ }^{2}$ & - & 39,8 \\
\hline 13 & Álcool etoxilado primário ramificado & Hidrocarboneto & Não iônico & 11,4 & 57 \\
\hline 14 & Álcool etoxilado primário ramificado & Hidrocarboneto & Não iônico & 12,4 & 64 \\
\hline 15 & Álcool etoxilado primário ramificado & Hidrocarboneto & Não iônico & 14,5 & 72,5 \\
\hline 16 & Álcool secundário etoxilado & Hidrocarboneto & Não iônico & 13,3 & 66 \\
\hline 17 & Álcool secundário etoxilado & Hidrocarboneto & Não iônico & 15,6 & 77 \\
\hline 18 & Álcool secundário etoxilado & Hidrocarboneto & Não iônico & 17,5 & 87 \\
\hline 19 & Álcool secundário etoxilado & Hidrocarboneto & Aniônico² & - & 58,6 \\
\hline 20 & Álcool secundário etoxilado & Hidrocarboneto & Aniônico ${ }^{2}$ & - & 70,2 \\
\hline 21 & Álcool secundário etoxilado & Hidrocarboneto & Aniônico $^{2}$ & - & 82,5 \\
\hline
\end{tabular}

${ }^{1}$ Relação entre as frações hidrofóbica e hidrofílica. ${ }^{2}$ Fosfatado.

As estruturas químicas dos surfactantes utilizados foram as seguintes:

Fluorsurfactante não-iônico:

$\mathrm{F}\left[\mathrm{CF}_{2} \mathrm{CF}_{2}\right]_{\mathrm{Y}} \mathrm{CH}_{2} \mathrm{CH}_{2} \mathrm{O}-\left[\mathrm{CH}_{2} \mathrm{CH}_{2} \mathrm{O}\right]_{\mathrm{X}} \mathrm{H}$, em que: $\mathrm{Y}=1$ 9 e $\mathrm{X}=0-25$.

Fluorsurfactante aniônico:

$\mathrm{F}\left[\mathrm{CF}_{2} \mathrm{CF}_{2}\right]_{\mathrm{Z}}\left[\mathrm{CH}_{2} \mathrm{CH}_{2} \mathrm{O}\right]_{\mathrm{X}} \mathrm{PO}\left(\mathrm{ONH}_{4}\right)_{\mathrm{Y}}$, em que $\mathrm{Z}=1$ $7 ; \mathrm{X}=1-2$; e $\mathrm{Y}=1-2$, sendo $\mathrm{X}+\mathrm{Y}=3$.

Surfactante silicone:

$$
\begin{gathered}
\mathrm{CH}_{3} \\
\left(\mathrm{CH}_{3}\right)_{3} \mathrm{Si}-\mathrm{O}-\mathrm{Si}-\mathrm{O}-\mathrm{Si}\left(\mathrm{CH}_{3}\right)_{3} \\
\mathrm{I} \mathrm{CH}_{2} \\
\mathrm{I}-\left[\mathrm{CH}_{2}-\mathrm{CH}_{2}-\mathrm{O}\right]_{8}-\mathrm{CH}_{3}
\end{gathered}
$$

Surfactantes à base de hidrocarbonetos:

Os surfactantes à base de hidrocarbonetos foram álcoois etoxilados, com cadeias lipofílicas contendo 12-14 carbonos e 4-30 moles de óxido de eteno na fração hidrofílica. As estruturas básicas desses surfactantes estão apresentadas abaixo:

Álcool linear não iônico e álcool linear aniônico:

$\mathrm{CH}_{3}-\left[\mathrm{CH}_{2}\right]_{\mathrm{X}}-\mathrm{O}-\left[\mathrm{CH}_{2} \mathrm{CH}_{2} \mathrm{O}\right]_{\mathrm{Y}} \mathrm{H}$ - onde $\mathrm{X}=11-13$ carbonos; $\mathrm{Y}=4-23$ moles de óxido de eteno. $\mathrm{O}$ grupo aniônico utilizado foi o fosfato.

Álcool ramificado primário não iônico:

$\left(\mathrm{CH}_{3}\right)_{2} \mathrm{CH}-\left[\mathrm{CH}_{2}\right]_{\mathrm{X}}-\mathrm{O}-\left[\mathrm{CH}_{2} \mathrm{CH}_{2} \mathrm{O}\right]_{\mathrm{Y}} \mathrm{H}$-, sendo $\mathrm{X}=9-11 \mathrm{e}$ $\mathrm{Y}=6-12$.
Álcool secundário não iônico e álcool secundário aniônico:

$$
\begin{gathered}
\mathrm{CH}_{3}\left[\mathrm{CH}_{2}\right]_{\mathrm{X} 1-\mathrm{X} 2}-\mathrm{CH}-\left[\mathrm{CH}_{2}\right]_{\mathrm{Y} 1-\mathrm{Y} 2} \mathrm{CH}_{3} \\
\mathrm{O}-\left[\mathrm{CH}_{2} \mathrm{CH}_{2} \mathrm{O}\right]_{\mathrm{Z}} \mathrm{H}
\end{gathered}
$$

$\mathrm{X} 1=1-5, \mathrm{Y} 1=1-6, \mathrm{X} 1+\mathrm{Y} 1=11 ; \mathrm{X} 2=1-4, \mathrm{Y} 2=1-5$, $\mathrm{X} 2+\mathrm{Y} 2=9 ; \mathrm{Z}=9-30$. O grupo aniônico foi o fosfato.

$\mathrm{Na}$ fase 2 do estudo, por causa de melhores resultados obtidos na fase 1 , foram selecionados apenas surfactantes à base de álcool, com carbonos da fração hidrófoba variando de 12-14 e com 4-30 moles de óxido de eteno.

Os cozimentos kraft foram realizados em digestor laboratorial rotativo dotado de quatro reatores com capacidade de dois litros cada um. As condições de cozimento foram adotadas de forma a alcançar número kappa em torno de 18 para o teste-referência sem surfactante. Foram utilizadas as seguintes condições para todos os cozimentos: cavacos $=250 \mathrm{~g}$ a.s., álcali efetivo $=17 \%$, sulfidez $=25 \%$; relação licor $/$ madeira $=4 / 1$, temperatura de cozimento $=168{ }^{\circ} \mathrm{C}$, tempo até temperatura $=90$ minutos; e tempo à temperatura $=$ 60 minutos. A dosagem de surfactante foi sempre 0,05\% base madeira seca. Os surfactantes foram adicionados ao licor de cozimento, homogeneizados e, posteriormente, colocados no reator contendo os cavacos. Para cada surfactante foram realizados, simultaneamente, três cozimentos mais um cozimento-referência sem o surfactante.

Ao final do cozimento, a polpa foi lavada em tela de 150 mesh com água em abundância, para a máxima remoção do licor residual. A individualização das fibras

R. Árvore, Viçosa-MG, v.28, n.6, p.911-917, 2004 
foi realizada num "hidrapulper" laboratorial de $201 \mathrm{e}$ a polpa, depurada em equipamento laboratorial Voith, com fendas de $0,2 \mathrm{~mm}$ de aberturas, onde foi coletado o rejeito do cozimento. A polpa depurada foi desaguada por centrifugação, desagregada e armazenada em sacos de polietileno. As operações de descarga, lavagem, depuração e desagregação das polpas foram realizadas de forma semelhante para minimizar possíveis efeitos nos resultados. As análises das polpas para número kappa, viscosidade e teor de extrativos solúveis em DCM foram realizadas conforme normas TAPPI (T236 om-99, T230 om-99 e T204 cm-97).

Cada surfactante foi avaliado comparando os resultados obtidos com e sem a sua aplicação. A comparação entre as médias de cada propriedade, com e sem a aplicação de surfactante, foi realizada utilizando o teste de Tukey a 5\% de probabilidade. Para avaliação da eficiência de remoção de extrativos lipofílicos, foi determinado o teor de extrativos solúveis em diclorometano, (DCM) nas polpas marrons. As características da polpação avaliadas foram o rendimento depurado, o número kappa, a viscosidade, o teor de rejeito e o álcali consumido. Na fase 2 dos estudos foi, ainda, avaliado o efeito do teor de óxido de eteno da molécula do surfactante no teor de extrativos lipofílicos remanescentes nas polpas.

\section{RESULTADOS E DISCUSSÃO}

\section{Fase 1}

No Quadro 3 são mostrados os resultados dos cozimentos realizados na fase 1 dos estudos.
Esperava-se, com base em informações de literatura (SANTOS, 1999), que a penetração do licor de cozimento fosse mais eficiente com o uso de surfactantes. Isso contribuiria para obter cozimentos mais uniformes, com maior grau de deslignificação e menor teor de rejeito. Entretanto, a utilização desses surfactantes não apresentou, de modo geral, resultados tecnológicos satisfatórios, conforme pode ser verificado no Quadro 3. Algumas possíveis razões para explicar a não-eficiência dos surfactantes poderiam ser a forma como foram aplicados, a dosagem utilizada ou, talvez mais provável, a instabilidade química ou térmica das moléculas nas condições do cozimento kraft.

Como pode ser verificado no Quadro 3, o rendimento depurado, o número kappa e o consumo de álcali não foram afetados pela aplicação de surfactantes. Entretanto, houve redução de $39 \%$ no teor de rejeito quando foram utilizados os surfactantes $\mathrm{n}^{\circ \mathrm{s}} 4,5$ e 9 , todos à base de hidrocarboneto. As melhores viscosidades, estatisticamente significativas, foram alcançadas com um dos surfactantes fluorados (cozimento $\mathrm{n}^{\circ} 2$ ) e com três surfactantes à base de hidrocarbonetos (cozimentos 4, 7 e 8 ). Os surfactantes fluorados e os siliconados, embora considerados grandes redutores da tensão superficial, não apresentaram remoção significativa de extrativos na etapa de cozimento. Apenas um dos surfactantes de álcool etoxilado, o do cozimento $\mathrm{n}^{\circ} 8$, proporcionou remoção significativa de extrativos.

Quadro 3 - Média dos resultados dos cozimentos da fase 1, com e sem surfactantes Table 3 - Average results of kraft pulping with and without surfactants (phase 1)

\begin{tabular}{|c|c|c|c|c|c|c|c|}
\hline $\begin{array}{l}\text { Número } \\
\text { Cozimento }\end{array}$ & Surfactante & $\begin{array}{c}\mathrm{DCM}^{1} \\
(\%)\end{array}$ & $\begin{array}{r}\text { Rend. } \\
(\%)\end{array}$ & $\begin{array}{c}\text { Número } \\
\text { Kappa }\end{array}$ & $\begin{array}{c}\text { Rejeitos } \\
(\%)\end{array}$ & $\begin{array}{c}\text { Álcali } \\
\text { Consumido }(\%)\end{array}$ & $\begin{array}{r}\text { Viscosidade } \\
\left(\mathrm{mPa} \cdot \mathrm{s}^{-1}\right)\end{array}$ \\
\hline 1 & Fluorado & $0,220^{\mathrm{a}}$ & $52,9^{a}$ & $17,1^{\mathrm{a}}$ & $0,23^{\mathrm{a}}$ & $86,8^{a}$ & $48,5^{\mathrm{a}}$ \\
\hline 2 & Fluorado & $0,202^{\mathrm{a}}$ & $53,0^{\mathrm{a}}$ & $17,5^{\mathrm{a}}$ & $0,27^{\mathrm{a}}$ & $86,8^{\mathrm{a}}$ & $49,6^{b}$ \\
\hline 3 & Silicone & $0,227^{a}$ & $52,5^{\mathrm{a}}$ & $17,9^{\mathrm{a}}$ & $0,27^{\mathrm{a}}$ & $87,8^{\mathrm{a}}$ & $48,6^{\mathrm{a}}$ \\
\hline 4 & Álcool etoxilado linear & $0,151^{\mathrm{a}}$ & $53,1^{\mathrm{a}}$ & $17,2^{\mathrm{a}}$ & $0,17^{\mathrm{b}}$ & $86,7^{\mathrm{a}}$ & $50,0^{\mathrm{b}}$ \\
\hline 5 & Álcool etoxilado linear & $0,146^{\mathrm{a}}$ & $52,8^{\mathrm{a}}$ & $17,6^{\mathrm{a}}$ & $0,17^{b}$ & $87,4^{\mathrm{a}}$ & $48,3^{\mathrm{a}}$ \\
\hline 6 & Álcool etoxilado linear & $0,149^{a}$ & $52,7^{\mathrm{a}}$ & $17,8^{\mathrm{a}}$ & $0,23^{\mathrm{a}}$ & $87,0^{\mathrm{a}}$ & $48,4^{\mathrm{a}}$ \\
\hline 7 & Álcool etoxilado linear & $0,132^{\mathrm{a}}$ & $52,6^{\mathrm{a}}$ & $18,1^{\mathrm{a}}$ & $0,30^{\mathrm{a}}$ & $87,3^{\mathrm{a}}$ & $49,0^{\mathrm{b}}$ \\
\hline 8 & Álcool etoxilado linear & $0,116^{\mathrm{b}}$ & $52,6^{\mathrm{a}}$ & $17,4^{\mathrm{a}}$ & $0,20^{\mathrm{a}}$ & $87,1^{\mathrm{a}}$ & $48,9^{\mathrm{b}}$ \\
\hline 9 & Álcool etoxilado linear & $0,164^{\mathrm{a}}$ & $52,8^{\mathrm{a}}$ & $17,8^{\mathrm{a}}$ & $0,17^{b}$ & $87,4^{\mathrm{a}}$ & $47,3^{\mathrm{a}}$ \\
\hline 10 & Sem surfactante & $0,188^{\mathrm{a}}$ & $52,8^{\mathrm{a}}$ & $17,6^{\mathrm{a}}$ & $0,28^{\mathrm{a}}$ & $86,9^{\mathrm{a}}$ & $47,1^{\mathrm{a}}$ \\
\hline
\end{tabular}

${ }^{1}$ Médias sobrescritas pela mesma letra não diferem estatisticamente entre si, pelo teste de Tukey a 5\% de probabilidade.

R. Árvore, Viçosa-MG, v.28, n.6, p.911-917, 2004 
Estudos desenvolvidos com utilização de álcoois etoxilados na etapa de polpação têm demonstrado resultados favoráveis na redução do número kappa e no decréscimo do teor de resina (FIŠEROVÁ e LU•ÁKOVÁ, 2000; DUGGIRALA, 1999b). Informações de literatura e alguns resultados favoráveis obtidos na primeira fase deste estudo, indicando maior potencial dos álcoois etoxilados, é que determinaram a seleção deste tipo de surfactante para estudos complementares na fase 2 dos estudos.

\section{Fase 2}

No Quadro 4 são mostrados os cozimentos realizados com utilização de surfactantes à base de hidrocarboneto na fase 2 dos estudos.

Apesar de uma das finalidades da utilização dos tenso-ativos neste trabalho ter sido a melhoria da seletividade da polpação, os efeitos no rendimento depurado, no número kappa e no teor de rejeito não foram significativos ou foram mínimos. A dosagem de $0,05 \%$ dos surfactantes utilizada neste estudo talvez não tenha sido suficiente para alcançar resultados de seletividade mais expressivos, embora, em alguns casos, tenham sido alcançados resultados favoráveis e estatisticamente significativos. Conforme pode ser observado no Quadro 4, os rendimentos depurados obtidos com aplicação de surfactantes foram um pouco superiores na maioria dos princípios ativos utilizados, sendo os aumentos de rendimento obtidos com os surfactantes $\mathrm{n}^{\circ \mathrm{s}} 12,18$ e 21 estatisticamente significativos. O surfactante $\mathrm{n}^{\circ} 21$ (álcool etoxilado secundário, aniônico, com $82,5 \%$ de óxido de eteno) foi o que apresentou o maior rendimento depurado, $1,1 \%$ superior ao do cozimento sem surfactante. Apenas um dos álcoois etoxilados, o do cozimento ${ }^{\circ} 14$, é que apresentou efeito favorável e estatisticamente significativo na deslignificação, tendo o número kappa desse cozimento sido $2,8 \%$ inferior ao do cozimento sem aplicação de surfactante. O resultado mais expressivo foi alcançado pelo surfactante $\mathrm{n}^{\circ} 18$, na redução do teor de rejeitos, que foi $31,6 \%$ inferior ao obtido sem aplicação de surfactante. Em relação à viscosidade das polpas, a aplicação dos diferentes surfactantes não apresentou nenhum afeito estatisticamente significativo.

\section{Remoção de extrativos lipofílicos}

Neste estudo, os melhores resultados para remoção de extrativos, medidos pelo teor de extrativos solúveis em DCM na polpa, foram obtidos com álcoois etoxilados. No Quadro 4 pode ser observado que todos os álcoois etoxilados resultaram em teores de extrativos DCM inferiores ao da polpa produzida sem surfactante. Os álcoois etoxilados lineares, tanto o não iônico quando o aniônico, utilizados nos cozimentos $\mathrm{n}^{\text {os }} 11$ e 12 , ocasionaram expressivas remoções de extrativos. Esses álcoois proporcionaram polpas com teores de extrativos 60 e $40 \%$ inferiores, respectivamente, ao da polpa produzida sem surfactante. Essa redução no teor de substâncias lipofílicas na polpa é muito desejável, uma vez que esses extrativos podem gerar problemas de deposição de "pitch" em etapas subseqüentes ou comprometer a qualidade da polpa. Esse efeito favorável de remoção de substâncias lipofílicas durante o cozimento já foi, também, detectado por outros autores (FIŠEROVÁ eLU•ÁKOVÁ, 2000; DUGGIRALA, 1999b). Isso significa que esses tensoativos podem ser utilizados na etapa de polpação, tanto como uma alternativa para controlar a deposição de pitch quanto para aumentar o grau de pureza da polpa, podendo resultar em benefícios posteriores no processamento da polpa. Polpa com baixo teor de impureza é um requisito primordial, por exemplo, para a fabricação de derivados de celulose.

Os extrativos da madeira de eucalipto são, em grande parte, neutros e insolúveis no licor de cozimento e estão situados em células de parênquima e, portanto, de difícil acesso. Uma explicação para o bom desempenho desses álcoois etoxilados na remoção dos extrativos lipofílicos pode ter sido suas propriedades de umectação e solubilização dessas substâncias no interior das células e, posteriormente, lixiviação destas para o exterior das células, mantendo-as dispersas e facilitando sua remoção na etapa de lavagem.

\section{Efeito do teor de óxido de eteno da molécula do surfactante na remoção de extrativos lipofílicos da madeira}

O teor de óxido de eteno na molécula de um surfactante hidrocarboneto tende a reduzir a tensão superficial da solução aquosa e, conseqüentemente, aumentar o poder de penetração e dissolução da solução. Entretanto, não foi encontrada, nas literaturas consultadas, nenhuma referência que fizesse avaliação do teor de óxido de eteno no cozimento e na qualidade da polpa. Essa avaliação foi realizada por Borchart et al. (1997) e O'Mera e Paterson (1960) em etapas de

R. Árvore, Viçosa-MG, v.28, n.6, p.911-917, 2004 
extração cáustica e de lavagem da polpa marrom, mas não no cozimento. Em razão da ampla faixa de variação do teor de óxido de eteno dos álcoois utilizados neste estudo (48,6 a $87 \%$ ) e da pequena faixa de variação do número de carbonos na fração hidrófoba das moléculas $\left(\mathrm{C}_{12} \mathrm{a} \mathrm{C}_{14}\right)$, foi possível avaliar o efeito do teor do óxido de eteno nas características da polpação. Não foram encontradas correlações satisfatórias, exceto com relação ao teor de extrativos das polpas. Na Figura 1 é mostrado o efeito do teor de óxido de eteno da molécula do surfactante no teor de extrativos solúveis em DCM nas polpas. Pode ser observado, tanto nos álcoois não iônicos quanto aniônicos, maior remoção de extrativos lipofílicos da madeira para teores mais baixos de óxido de eteno na molécula do surfactante. Tais resultados confirmam estudos realizados por Borchart et al. (1997) e O’Mera e Paterson (1960).

A maior aptidão para remoção de substâncias lipofílicas da madeira apresentada pelas moléculas de menor grau de etoxilação pode, possivelmente, ser atribuída aos seguintes fatores:

- Maior afinidade dos surfactantes com menor teor de óxido de eteno por substâncias lipofílicas da madeira, em comparação com as moléculas de maior grau de etoxilação, que são mais hidrofílicas.

- Melhor acessibilidade ao interior das células de parênquima, onde está situada a maioria dos extrativos da madeira.
- Maior facilidade de locomoção em razão de apresentarem pesos moleculares mais baixos.

- Maior capacidade de redução da tensão superficial de líquidos, portanto maior poder de molhabilidade.

- Maior capacidade de manter dispersos os extrativos da madeira, dificultando sua deposição sobre a polpa ou em locais de difícil acesso durante o processamento da polpa.

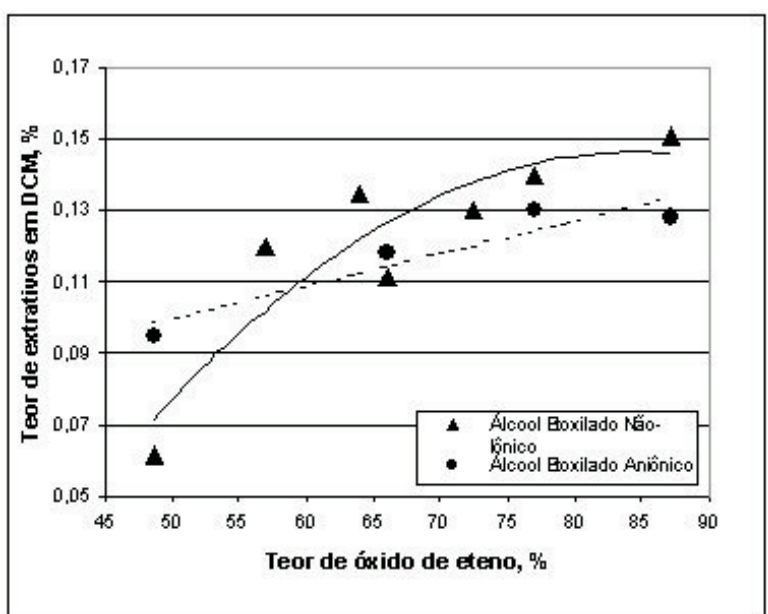

Figura 1 - Efeito do teor de óxido de eteno na remoção de extrativos durante o cozimento "Kraft", em álcoois não iônicos e aniônicos.

Figure 1-Effect of ethene oxide content on extractives removal during kraft pulping for non-ionic and anionic alcohols.

Quadro 4 - Médias dos resultados dos cozimentos com e sem a utilização de surfactantes Table 4 -Average results with and without surfactants

\begin{tabular}{lccccccc}
\hline $\begin{array}{l}\text { Número } \\
\text { Cozimento }\end{array}$ & Surfactante & $\begin{array}{c}\text { DCM } \\
(\%)\end{array}$ & $\begin{array}{c}\text { Rend. } \\
(\%)\end{array}$ & $\begin{array}{c}\text { Número } \\
\text { Kappa }\end{array}$ & $\begin{array}{c}\text { Rejeitos } \\
(\%)\end{array}$ & $\begin{array}{c}\text { Álcali } \\
\text { Consumido }(\%)\end{array}$ & $\begin{array}{c}\text { Viscosidade } \\
\left(\mathrm{mPa} . \mathrm{s}^{-1}\right)\end{array}$ \\
\hline 11 & Álcool etoxilado linear & $0,062^{\mathrm{b}}$ & $53,0^{\mathrm{a}}$ & $17,7^{\mathrm{a}}$ & $0,17^{\mathrm{a}}$ & $86,9^{\mathrm{a}}$ & $47,5^{\mathrm{a}}$ \\
12 & Álcool etoxilado linear & $0,095^{\mathrm{b}}$ & $53,1^{\mathrm{b}}$ & $17,7^{\mathrm{a}}$ & $0,27^{\mathrm{a}}$ & $87,0^{\mathrm{a}}$ & $46,3^{\mathrm{a}}$ \\
13 & Álcool etoxilado primário ramificado & $0,120^{\mathrm{a}}$ & $52,9^{\mathrm{a}}$ & $17,7^{\mathrm{a}}$ & $0,20^{\mathrm{a}}$ & $87,2^{\mathrm{a}}$ & $46,0^{\mathrm{a}}$ \\
14 & Álcool etoxilado primário ramificado & $0,135^{\mathrm{a}}$ & $53,0^{\mathrm{a}}$ & $17,6^{\mathrm{b}}$ & $0,17^{\mathrm{a}}$ & $87,2^{\mathrm{a}}$ & $44,2^{\mathrm{a}}$ \\
15 & Álcool etoxilado primário ramificado & $0,130^{\mathrm{a}}$ & $53,0^{\mathrm{a}}$ & $17,9^{\mathrm{a}}$ & $0,20^{\mathrm{a}}$ & $87,3^{\mathrm{a}}$ & $47,2^{\mathrm{a}}$ \\
16 & Álcool etoxilado secundário & $0,112^{\mathrm{a}}$ & $53,0^{\mathrm{a}}$ & $17,9^{\mathrm{a}}$ & $0,20^{\mathrm{a}}$ & $86,7^{\mathrm{a}}$ & $43,9^{\mathrm{a}}$ \\
17 & Álcool etoxilado secundário & $0,140^{\mathrm{a}}$ & $52,7^{\mathrm{a}}$ & $18,5^{\mathrm{a}}$ & $0,20^{\mathrm{a}}$ & $87,0^{\mathrm{a}}$ & $44,9^{\mathrm{a}}$ \\
18 & Álcool etoxilado secundário & $0,151^{\mathrm{a}}$ & $53,2^{\mathrm{b}}$ & $17,7^{\mathrm{a}}$ & $0,13^{\mathrm{b}}$ & $86,9^{\mathrm{a}}$ & $44,5^{\mathrm{a}}$ \\
19 & Álcool etoxilado secundário & $0,118^{\mathrm{a}}$ & $52,9^{\mathrm{a}}$ & $18,2^{\mathrm{a}}$ & $0,20^{\mathrm{a}}$ & $87,0^{\mathrm{a}}$ & $43,5^{\mathrm{a}}$ \\
20 & Álcool etoxilado secundário & $0,130^{\mathrm{a}}$ & $53,0^{\mathrm{a}}$ & $18,3^{\mathrm{a}}$ & $0,33^{\mathrm{a}}$ & $87,2^{\mathrm{a}}$ & $45,8^{\mathrm{a}}$ \\
21 & Álcool etoxilado secundário & $0,128^{\mathrm{a}}$ & $53,3^{\mathrm{b}}$ & $17,8^{\mathrm{a}}$ & $0,17^{\mathrm{a}}$ & $87,1^{\mathrm{a}}$ & $44,9^{\mathrm{a}}$ \\
22 & Sem surfactante & $0,158^{\mathrm{a}}$ & $52,7^{\mathrm{a}}$ & $18,1^{\mathrm{a}}$ & $0,19^{\mathrm{a}}$ & $87,2^{\mathrm{a}}$ & $45,0^{\mathrm{a}}$ \\
\hline
\end{tabular}

${ }^{1}$ Médias sobrescritas pela mesma letra não diferem estatisticamente entre si, pelo teste de Tukey a 5\% de probabilidade.

R. Árvore, Viçosa-MG, v.28, n.6, p.911-917, 2004 


\section{CONCLUSÕES}

Os resultados obtidos neste estudo indicaram que:

- Dentre os três tipos de surfactantes avaliados neste estudo (fluorsurfactantes, siliconados e álcoois etoxilados), os álcoois etoxilados apresentaram os melhores benefícios quanto ao teor de rejeitos, viscosidade da polpa e remoção de extrativos.

- Alguns álcoois etoxilados apresentaram efeito favorável na remoção de extrativos da madeira na etapa de cozimento, tendo os melhores resultados sido alcançados com os álcoois etoxilados lineares com menor teor de óxido de eteno.

- O teor de óxido de eteno na molécula dos álcoois etoxilados apresentou efeito inversamente proporcional à eficiência de remoção de substâncias lipofílicas da madeira.

- Foram alcançados aumentos de rendimento na polpação kraft $(0,4$ a 0,6\%) quando se utilizaram o álcool etoxilado linear aniônico com $39,8 \%$ de óxido de eteno e os álcoois etoxilados secundários com 87 e $82,5 \%$ de óxido de eteno.

- Um único surfactante, o álcool etoxilado primário ramificado não iônico com $64 \%$ de óxido de eteno, causou redução do número kappa de 18,1 para 17,6 . Todos os outros surfactantes analisados não apresentaram efeito estatisticamente significativo na deslignificação da madeira.

- A utilização de surfactantes à base de hidrocarboneto não apresentou, de modo geral, efeito na redução de rejeitos, tendo apenas um surfactante proporcionado redução significativa de $31 \%$ no teor de rejeitos (o álcool secundário etoxilado, não iônico, com $87 \%$ de óxido de eteno).

\section{AGRADECIMENTOS}

Seria difícil a realização do presente trabalho sem as significativas contribuições dos técnicos do Setor de Celulose e Papel da Universidade Federal de Viçosa, em especial a do analista Cássio Anderson M. Caetano e a da secretária Maria Auxiliadora de Souza Lima, e sem a importante ajuda financeira do CNPq. A todos, os sinceros agradecimentos dos autores.

\section{REFERÊNCIAS BIBLIOGRÁFICAS}

BORCHARDT, J.K.; BIANCALANA, R.P.; MAHONEY, C.L. Improved deresination agents: laboratory and mill results. In: PULPING CONFERENCE, 1997, San Francisco. Proceedings... San Francisco; 1997. p. 395-413.

CHEN, G.C. Application of a surfactant as a kraft pulping additive. Tappi Journal, v. 77, n. 2, p.125-128, 1994

DUGGIRALA, P.Y. Evaluation of surfactants as digester additives for kraft softwood pulping. Tappi Journal, v. 82, n.11, p.121-127, 1999a.

DUGGIRALA, P.Y. Evaluation of surfactant technology for bleachable and high yield hardwood kraft pulps. Appita Journal, v.52, n.4, p.305-311, 1999b.

FIŠEROVÁ, M.; LU•ÁKOVÁ, V. Aplicação de surfactantes como aditivos na polpação kraft. $O$ Papel, v.61, n.11, p.96-103, 2000.

O'MERA, D.; PATERSON, R.M.L. Deresination of sulfite pulps with nonionic surfactants. Tappi, v.43, n.11. p.927-933, 1960.

SANTOS, A.M.C.S. Fluorsurfactantes e a prevenção de defeitos de pintura.

Paint\&Pintura, n. 11, p. 140-144, 1999.

SILVA JR., F.G. et al. Experiências industriais da Votorantim Celulose e Papel na polpação kraft com uso de antraquinona e surfactante. In: CONGRESSO ABTCP, 30. , 1997, São Paulo. Anais... São Paulo: 1997. p.191-204.

TECHNICALASSOCIATION OF THE AMERICAN PULP AND PAPER INDUSTRY - TAPPI. Test methods. Atlanta: 2000-2001. 